\title{
The Well-being Questionnaire: evidence for a three- factor structure with 12 items (W-BQ12)
}

\author{
F. POUWER, ${ }^{1}$ F. J. SNOEK, H. M. VAN DER PLOEG, H. J. ADĖR AND R. J. HEINE \\ From the Department of Medical Psychology, Department of Endocrinology and Department of Clinical \\ Epidemiology and Biostatistics, Research Institute for Endocrinology, Reproduction and Metabolism, \\ Vrije Universiteit, Amsterdam, The Netherlands
}

\begin{abstract}
Background. The Well-being Questionnaire (W-BQ) has been designed to measure psychological well-being in people with a chronic somatic illness and is recommended by the World Health Organization for widespread use. However, studies into the factor structure of this instrument are still limited and their findings are inconsistent. This study aimed to investigate the factor structure of the Dutch version of the W-BQ.

Methods. A cross-validation design was used. A total of 1472 people with diabetes completed the $\mathrm{W}-\mathrm{BQ}$ and were randomly assigned to group A or B. In group A $(N=736)$, exploratory factor analyses were conducted. Group B $(N=736)$ was split up into four subgroups of male or female patients with type 1 or type 2 diabetes. In these subgroups, confirmatory factor analyses were employed to test the model(s) developed in group A and the two models described in the literature (four-factor model with 22 items and a three-factor model with 12 items).
\end{abstract}

Results. Exploratory factor analyses yielded a three-factor model with 21 items (negative well-being, energy and positive well-being). In the subgroups of group B confirmatory factor analyses only accepted the three-factor model with 12 items. This factor solution was stable across gender, type of diabetes and level of education.

Conclusions. The best description of the factor structure of the Dutch translation of the W-BQ was given by a three-factor solution with 12 items (W-BQ12), measuring positive well-being (four items), negative well-being (four items) and energy (four items).

\section{INTRODUCTION}

Measuring psychological well-being in patients with physical illness such as diabetes mellitus has received increasing attention in the past years. Substantial research suggests that the prevalence of depression and anxiety is about three times higher in people with diabetes when compared with the general population (Gavard et al. 1993; Peyrot \& Rubin, 1997). Depression and anxiety interfere considerably with the quality of life of patients with diabetes and are likely to have a negative effect on their

1 Address for correspondence; Dr François Pouwer, Department of Medical Psychology, Vrije Universiteit, Van der Boechorststraat 7, 1081 BT, Amsterdam, The Netherlands. glycaemic control, thereby increasing the risk for complications of diabetes (Rubin \& Peyrot, 1992; Diabetes Control and Complications Trial Research Group, 1993; Lustman et al. 1998). It was also found that physicians underdiagnosed depression in 50-70\% of the cases (Coyne et al. 1995; Penn et al. 1997). Therefore, it is advised to monitor psychological well-being as a part of the routine medical care for people with diabetes and to use the Well-being Questionnaire (WBQ) for this purpose (Bradley \& Gamsu, 1994).

The W-BQ was developed as a generic measure of several aspects of psychological well-being. Since the W-BQ contains no diabetes specific questions, it is also considered to be a suitable instrument for use in people with other chronic 
diseases or in the general population (Bradley, 1994). To date, it has been used in samples consisting of people with diabetes, rheumatoid arthritis, schizophrenia and depression (Pincus et al. 1997).

In the development of the W-BQ, items pertaining to physical indicators of depression or distress (e.g. decreased libido or weight loss) were not included, since these symptoms can also be a sign of complications of diabetes or indicate hyper- or hypoglycaemia. Bradley (1994) described that a general well-being scale (22 items) and four subscales can be constructed: Depression (six items), Anxiety (six items), Energy (four items) and Positive Well-being (six items). The items of the Depression and the Anxiety subscales of the W-BQ stem from Zung's Self-rating Depression Scale (SDS) and Selfrating Anxiety Scale (SAS). Zung used diagnostic criteria of pervasive depressed affect and anxiety disorder in the construction of these questionnaires (Zung, 1965, 1974; Warr \& Parry, 1982; Warr et al. 1985). Yet, the W-BQ scales are not identical to the scales developed by Zung or Warr and colleagues, since the wording of three items was changed (e.g. 'My mind is as clear as it used to be' was changed into 'I find I can think quite clearly'). Besides, the response options were altered for undescribed reasons from a Likert scale consisting of ' 1 ' (a little of the time), '2' (some of the time), ' 3 ' (good part of the time) and ' 4 ' (most of the time) into a Likert scale ranging from ' 3 ' (all the time) to ' 0 ' (not at all). In the latter scale the response options ' 2 ' and ' 1 ' have no value labels. The items of the Energy as well as the Positive Wellbeing scale do not have a clear theoretical background; these items were developed after discussions with diabetologists and psychologists at a WHO-meeting (Bradley, 1994).

It was concluded that Bradley's four-factor structure was confirmed, except for the Energy scale (Wredling et al. 1995). Exploratory factor analyses in a Japanese sample of 464 patients with diabetes yielded a 12-item three-factor solution (Bradley, 1996), measuring Negative Well-being (four items), Energy (four items) and Positive Well-being (four items). The W-BQ was also regarded as a uni-dimensional scale that could be reduced to a 10-item scale (Bech et al. 1996). It was concluded that this WHO (Ten) index was a sufficient measure to assess overall well-being, that was not intended to replace the four Bradley scales (Bech et al. 1996).

We conclude that the factor structure of the W-BQ has received only limited empirical assessment, with contradictory results. Therefore, the aim of the present study was to analyse the factor structure of the Dutch version of the W-BQ.

\section{METHOD}

\section{Subjects and procedure}

The Dutch Organization of Patients with Diabetes (DVN, Diabetes Vereniging Nederland) has drawn a random sample of 3000 subjects from a total of approximately 41000 members. The DVN mailed the booklet of questionnaires, two letters explaining the goals and procedures, and a pre-stamped response-envelope to the selected patients. Patients were invited to complete questions concerning demographic and medical characteristics as well as a set of questionnaires, including the Dutch version of the W-BQ (Pouwer et al. 1998). A crossvalidation design was used. The total sample of $1472(49 \%)$ patients who responded, was randomly divided into group $\mathrm{A}(N=736)$ and $\mathrm{B}$ $(N=736)$. In group $\mathrm{A}$, the factor structure of the W-BQ was investigated using exploratory factor analyses (EFA). Confirmatory factor analysis (CFA) allows a more powerful test of factorial validity than exploratory approaches do (Byrne, 1994). Several studies have found gender differences in psychological well-being (e.g. Bradley, 1994; Wilhelm et al. 1997). Also, type 1 and type 2 diabetes are two different diseases. Patients who were younger than 40 years when their diabetes was diagnosed and had to use insulin from the start were regarded as patients with type 1 diabetes. Those who did not meet these criteria were considered as having type 2 diabetes. In order to investigate the stability of different factor solutions for the WBQ across gender and type of diabetes, CFAs were performed in four different subgroups of group B. Group $B_{1}$ consisted of 187 men with type 1 diabetes, group $B_{2}$ of 167 women with type 1 diabetes, group $B_{3}$ of 169 men with type 2 diabetes and group $B_{4}$ of 196 women with type 2 diabetes. The fit of the following models was 
tested: the four-factor model with 22 items (Bradley, 1994), the three-factor model with 12 items (Bradley, 1996) and the model(s) developed in group A.

\section{Statistics}

SPSS 7.5 and EQS 5.1 for Windows were used to perform EFA and CFA respectively (Bentler, 1989; SPSS Inc., 1997). Items loading $\geqslant|0 \cdot 40|$ on one factor and $<|0 \cdot 30|$ on any other factor were accepted (Floyd \& Widaman, 1995). Since the W-BQ factors are highly correlated (Bradley, 1994), EFA with oblique rotation (direct oblimin) was used (Floyd \& Widaman, 1995). For CFA, maximum likelihood (ML) estimation method was used (Byrne, 1994). The distribution of the W-BQ is multivariately non-normal (Petterson et al. 1998). Therefore, the Robust Comparative Fit Index (CFI*) was used as the most appropriate measure to evaluate the fit of the models to the data (West et al. 1995). A $\mathrm{CFI}^{*} \geqslant 0.90$ is generally considered as an indication of adequate fit of a model. The ML $\chi^{2}$ and the robust $\mathrm{S}-\mathrm{B}$ scaled $\chi^{2}$ were also calculated (West et al. 1995). Yet, both fit indexes have an important disadvantage. With a large sample size they are often too powerful. In that case, trivial deviations of the observed covariance and the estimated covariance on the basis of the model often lead to a significant $\chi^{2}$ and incorrect rejection of the model (Byrne, 1994). Therefore, we relied on the $\mathrm{CFI}^{*}$, a fit-index that is based on the robust scaled S-B $\chi^{2}$. In the EFAs we used the pairwise method to handle missing values. In the CFAs, cases with more $>10 \%$ missing values were deleted since the EQSprogram cannot run with missing values. A maximum of two missing values was estimated by calculating the mean for that subject, using the remaining items of the same scale described in the appropriate model.

\section{RESULTS}

\section{Sample characteristics}

Sample characteristics are shown in Table 1. Mean age was 51 (S.D. 15.5) years, ranging from 18 to 82 years. It appeared that 739 patients (51\%) had type 1 diabetes, and 701 (49\%) had type 2 diabetes. Due to missing data, the type of diabetes of 32 patients could not be determined.
Table 1. Self-reported sample characteristics

\begin{tabular}{|c|c|}
\hline Variable & $\%(N)$ \\
\hline \multicolumn{2}{|l|}{ Gender } \\
\hline Female & $49(722)$ \\
\hline Male & $51(747)$ \\
\hline \multicolumn{2}{|l|}{ Marital status } \\
\hline Married/cohabit & $75(1103)$ \\
\hline Not married & $15(218)$ \\
\hline Widowed & $7(97)$ \\
\hline Divorced & $3(48)$ \\
\hline \multicolumn{2}{|l|}{ Age (years) } \\
\hline$<30$ & $12(168)$ \\
\hline $30-39$ & $15(222)$ \\
\hline $40-49$ & $16(232)$ \\
\hline $50-59$ & $21(312)$ \\
\hline $60-69$ & $24(347)$ \\
\hline$\geqslant 70$ & $12(179)$ \\
\hline \multicolumn{2}{|l|}{ Highest completed education } \\
\hline Primary school & $12(171)$ \\
\hline Lower vocational & $19(259)$ \\
\hline General secondary & $20(277)$ \\
\hline Senior secondary/Senior general secondary & $26(363)$ \\
\hline Higher vocational/University & $23(318)$ \\
\hline \multicolumn{2}{|l|}{ Duration of diabetes (years) } \\
\hline $0-5$ & $20(294)$ \\
\hline $6-10$ & $18(262)$ \\
\hline $11-19$ & $30(432)$ \\
\hline $20-29$ & $18(256)$ \\
\hline$\geqslant 30$ & $14(204)$ \\
\hline
\end{tabular}

Most subjects were born in The Netherlands $(96 \%)$. From $t$ and $\chi^{2}$ tests no significant differences were found between group A and B concerning age, duration of diabetes, age of onset of diabetes, gender, type of diabetes, marital status or education.

In the whole sample, 67 subjects $(4.6 \%)$ had one or two missing values and 55 subjects had more than two missing values $(3 \cdot 7 \%)$. For the 22 individual $\mathrm{W}-\mathrm{BQ}$ items, the percentages of subjects with a missing value ranged from $2.9 \%$ for item 17 (happy) to $4 \cdot 2 \%$ for item 7 (feel nervous) and item 10 (feel like I'm falling apart). In group $\mathrm{B}_{3}$ as well as $\mathrm{B}_{4}$ seven cases had $>10 \%$ missing values and were therefore removed from the CFAs. In group $B_{1}$ and $B_{2}$ none of the subjects had $>10 \%$ missing values.

\section{Exploratory factor analyses in group A}

In group A, EFA revealed four factors with an eigenvalue $>1$. The first four eigenvalues before rotation were $9 \cdot 2,2 \cdot 0,1 \cdot 2$ and 1.0 (Table 2). Three forced factor solutions with respectively four, three and two factors were calculated. The 
Table 2. Forced two-, three- and four-factor solution after exploratory factor analyses of the 22 $W$-BQ items in group $A(\mathrm{~N}=736)$. Oblimin rotation was used, loadings $<|0 \cdot 30|$ are not shown and loadings $<|0 \cdot 40|$ are in parentheses

\begin{tabular}{|c|c|c|c|c|c|c|c|c|c|}
\hline \multirow[b]{3}{*}{$\begin{array}{l}\text { Shortened } \\
\text { item content }\end{array}$} & \multicolumn{9}{|c|}{ Factor solutions } \\
\hline & \multicolumn{2}{|c|}{ Dutch $2 \mathrm{~F} 20$} & \multicolumn{3}{|c|}{ Dutch $3 F 21$} & \multicolumn{4}{|c|}{ Dutch 4F22 } \\
\hline & $\begin{array}{c}\text { Positive } \\
\text { Well-being }\end{array}$ & $\begin{array}{l}\text { Negative } \\
\text { Well-being }\end{array}$ & $\begin{array}{c}\text { Positive } \\
\text { Well-being }\end{array}$ & $\begin{array}{l}\text { Negative } \\
\text { Well-being }\end{array}$ & Energy & $\begin{array}{c}\text { Positive } \\
\text { Well-being }\end{array}$ & $\begin{array}{l}\text { Negative } \\
\text { Well-being }\end{array}$ & Energy & Calmness \\
\hline \multicolumn{10}{|l|}{ Depression* } \\
\hline 1 Useful and needed & 0.75 & & 0.76 & & & $0 \cdot 75$ & & & \\
\hline 2 Crying spells & & $0 \cdot 71^{\mathrm{NWB}}$ & & $0.65^{\mathrm{NWB}}$ & & & $0.67^{\mathrm{NwB}}$ & & \\
\hline 3 Think clearly & 0.59 & & 0.59 & & & $0 \cdot 56$ & & & \\
\hline 4 Life pretty full & $0 \cdot 80$ & & $0 \cdot 80$ & & & 0.79 & & & \\
\hline $\begin{array}{l}5 \text { Downhearted and } \\
\text { blue }\end{array}$ & & $0 \cdot 69^{\mathrm{NWB}}$ & & $0 \cdot 60^{\mathrm{NWB}}$ & & & $0.63^{\mathrm{NWB}}$ & & \\
\hline 6 Enjoy things & $0 \cdot 74$ & & $0 \cdot 74$ & & & $0 \cdot 72$ & & & \\
\hline \multicolumn{10}{|l|}{ Anxiety* } \\
\hline 7 Nervous and anxious & & $0 \cdot 77$ & & $0 \cdot 72$ & & & $0 \cdot 72$ & & \\
\hline 8 Afraid for no reason & & $0 \cdot 87^{\mathrm{NWB}}$ & & $0 \cdot 89^{\text {NWB }}$ & & & $0 \cdot 88^{\text {NW }}$ & & \\
\hline 9 Upset or feel panicky & & $0 \cdot 81^{\mathrm{NWB}}$ & & $0 \cdot 81^{\mathrm{NWB}}$ & & & $0 \cdot 80^{\text {NWB }}$ & & \\
\hline 10 Falling apart & & 0.72 & & 0.74 & & & 0.74 & & \\
\hline 11 Calm and can sit still & & & $(0 \cdot 33)$ & & & & & & $0 \cdot 66$ \\
\hline 12 Good night's rest & & & & & $-0 \cdot 52$ & & & $(-0 \cdot 34)$ & $0 \cdot 73$ \\
\hline \multicolumn{10}{|l|}{ Energy* } \\
\hline 13 Energetic & $0 \cdot 64^{\mathrm{E}}$ & & & & $-0 \cdot 71^{\mathrm{E}}$ & $(0 \cdot 35)$ & & $-0 \cdot 64^{\mathrm{E}}$ & \\
\hline 14 Dull & & $0 \cdot 42^{\mathrm{E}}$ & & & $0 \cdot 79^{\mathrm{E}}$ & & & $0.73^{\mathrm{E}}$ & \\
\hline 15 Tired & & $0 \cdot 55^{\mathrm{E}}$ & & & $0 \cdot 81^{\mathrm{E}}$ & & & $0 \cdot 74^{\mathrm{E}}$ & \\
\hline 16 Fresh and rested & $0.57^{\mathrm{E}}$ & & & & $-0.69^{\mathrm{E}}$ & & & $-0.57^{\mathrm{E}}$ & $(0 \cdot 34)^{\mathrm{E}}$ \\
\hline \multicolumn{10}{|l|}{ Positive well-being* } \\
\hline 17 Happy with life & $0.73^{\text {PWB }}$ & & $0.71^{\mathrm{PWB}}$ & & & $0 \cdot 72^{\text {PWB }}$ & & & \\
\hline 18 Well adjusted to life & 0.76 & & $0 \cdot 71$ & & & 0.73 & & & \\
\hline 19 Live life I want to & $0 \cdot 68^{\mathrm{PWB}}$ & & $0.62^{\text {PWB }}$ & & & $0.64^{\mathrm{PWB}}$ & & & \\
\hline 20 Tackle daily tasks & $0 \cdot 61^{\mathrm{PWB}}$ & & $0 \cdot 46^{\text {PWB }}$ & & & $0 \cdot 53^{\mathrm{PWB}}$ & & $-0 \cdot 31^{\mathrm{PWB}}$ & \\
\hline 21 Cope with problems & $0 \cdot 61^{\text {PWB }}$ & & $0.54^{\mathrm{PWB}}$ & & & $0.55^{\mathrm{PWB}}$ & & & \\
\hline 22 Daily life interesting & $0 \cdot 83$ & & $0 \cdot 75$ & & & $0 \cdot 78$ & & & \\
\hline $\begin{array}{l}\text { Eigenvalue before } \\
\text { rotation }\end{array}$ & $9 \cdot 2$ & $2 \cdot 0$ & $9 \cdot 2$ & $2 \cdot 0$ & $1 \cdot 2$ & $9 \cdot 2$ & $2 \cdot 0$ & $1 \cdot 2$ & $1 \cdot 0$ \\
\hline $\begin{array}{l}\% \text { Variance before } \\
\text { rotation }\end{array}$ & $41 \cdot 8$ & $8 \cdot 9$ & $41 \cdot 8$ & $8 \cdot 9$ & $5 \cdot 7$ & $41 \cdot 8$ & $8 \cdot 9$ & $5 \cdot 7$ & $4 \cdot 7$ \\
\hline $\begin{array}{l}\text { Eigenvalue after } \\
\text { rotation }\end{array}$ & $8 \cdot 2$ & $6 \cdot 9$ & $7 \cdot 5$ & $6 \cdot 2$ & $6 \cdot 2$ & $7 \cdot 5$ & $6 \cdot 2$ & $4 \cdot 9$ & $2 \cdot 3$ \\
\hline
\end{tabular}

* The four-factor structure as described by Bradley (1994). The factor-loadings of the 12 items of the Japanese three-factor solution are labelled with an abbreviation of the name of the scale they were assigned to by Bradley (1996): Negative Well-being (NWB); Energy (E); Positive Well-being (PWB).

two-factor structure consisted of 20 items, with both factors accounting for $41.8 \%$ and $8.9 \%$ of the total item variance before rotation. Twelve positively worded items loaded on the first factor (Positive Well-being) and eight negatively worded items on the second factor (Negative Well-being). Item 11 (feel calm) and 12 (good night's rest) did not load $\geqslant|0 \cdot 40|$ on one of the factors of this two-factor solution that was named 'Dutch 2F20'.

The present three-factor solution was very similar to the three-factor solution with 12 items described in the literature (Bradley, 1996). The first factor of this solution consisted of ten positively worded well-being items (Positive Well-being), the second factor of six negatively worded well-being items (Negative Well-being). The third factor was composed of five items concerning energy or fatigue (Energy). The three factors explained $41.8 \%, 8.9 \%$ and $5.7 \%$ of the variance respectively. Item 11 (feel calm) did not load $\geqslant|0 \cdot 40|$ on one of the factors and was removed from that three-factor solution that was named 'Dutch $3 \mathrm{~F} 21$ '. In the four-factor solution, the items loaded in a way that was almost identical to the Dutch 3F21. The main 
Table 3. Evaluation of the three prespecified factor solutions for the $W$-BQ in group $B_{1-4}$

\begin{tabular}{lccccccc}
\hline \hline Model & Group $\dagger$ & $N$ & ML $\chi^{2}(\mathrm{df})$ & $P$ & $\mathrm{~S}-\mathrm{B} \chi^{2}$ & $P$ & CFI* $^{*}$ \\
\hline Bradley 4F-22 & $\mathrm{B}_{1}$ & 187 & $455(203)$ & $<0 \cdot 001$ & 322 & $<0 \cdot 001$ & $0 \cdot 89$ \\
Bradley 4F-22 & $\mathrm{B}_{2}$ & 167 & $512(203)$ & $<0 \cdot 001$ & 387 & $<0 \cdot 001$ & $0 \cdot 86$ \\
Bradley 4F-22 & $\mathrm{B}_{3}$ & 162 & $544(203)$ & $<0 \cdot 001$ & 412 & $<0 \cdot 001$ & $0 \cdot 84$ \\
Bradley 4F-22 & $\mathrm{B}_{4}$ & 189 & $500(203)$ & $<0 \cdot 001$ & 408 & $<0 \cdot 001$ & $0 \cdot 87$ \\
Bradley 3F-12 & $\mathrm{B}_{1}$ & 187 & $148(50)$ & $<0 \cdot 001$ & 100 & $<0 \cdot 001$ & $0 \cdot 91$ \\
Bradley 3F-12 & $\mathrm{B}_{2}$ & 167 & $167(50)$ & $<0 \cdot 001$ & 91 & $<0 \cdot 001$ & $0 \cdot 94$ \\
Bradley 3F-12 & $\mathrm{B}_{3}$ & 162 & $97(50)$ & $<0 \cdot 001$ & 70 & $<0 \cdot 001$ & $0 \cdot 97$ \\
Bradley 3F-12 & $\mathrm{B}_{4}$ & 189 & $173(49)$ & $<0 \cdot 001$ & 107 & $<0 \cdot 001$ & $0 \cdot 93 *$ \\
Dutch 3F-21 & $\mathrm{B}_{1}$ & 187 & $491(186)$ & $<0 \cdot 001$ & 323 & $<0 \cdot 001$ & $0 \cdot 86$ \\
Dutch 3F-21 & $\mathrm{B}_{2}$ & 167 & $524(186)$ & $<0 \cdot 001$ & 369 & $<0 \cdot 001$ & $0 \cdot 86$ \\
Dutch 3F-21 & $\mathrm{B}_{3}$ & 162 & $462(186)$ & $<0 \cdot 001$ & 351 & $<0 \cdot 001$ & $0 \cdot 87$ \\
Dutch 3F-21 & $\mathrm{B}_{4}$ & 189 & $511(186)$ & $<0 \cdot 001$ & 409 & $<0 \cdot 001$ & $0 \cdot 85$ \\
\hline \hline
\end{tabular}

ML $\chi^{2}$, maximum likelihood chi-square; S-B $\chi^{2}$, Satorra-Bentler scaled chi-square for non-normal distributed data; CFI*, Robust Comparative Fit Index based on the S-B $\chi^{2}$.

$\uparrow \mathrm{B}_{1}$ (men, type 1 diabetes), $\mathrm{B}_{2}$ (women, type 1 diabetes), $\mathrm{B}_{3}$ (men, type 2 diabetes) and $\mathrm{B}_{4}$ (women, type 2 diabetes)

$\$$ With correlated error between item 14 (dull) and 15 (tired).

difference was an extra two-item factor (Calmness), consisting of items 11 and 12 , which explained an additional $4.7 \%$ of the variance.

In the three- as well as the four-factor solution, the items with an Energy-content had high loadings on one Energy-factor. In the two-factor solution, the 'Energy-items' had relatively low factor loadings and dispersed across two factors. Therefore, we considered this two-factor solution as too simplistic and we decided not to test this model in group B. The four-factor solution was also considered as less appropriate, since it is generally accepted that scales should contain at least three items (Floyd \& Widaman, 1995). Thus, only the newly found three-factor model with 21 items (Dutch 3F21) was compared with the two models from the literature in group $\mathrm{B}_{1-4}$.

\section{Confirmatory factor analyses in group $B_{1-4}$}

In group $B_{1-4}$, we tested three models using CFA (Table 3). To be clear, the original four-factor solution with 22 items is mentioned 'Bradley 4 F22' while the three-factor solution with 12 items (W-BQ12) is referred to as 'Bradley 3F12' in the present article. The Bradley 4F22 and the Dutch 3F21 solutions appeared to have an inadequate fit in all four subgroups, with CFI*s $<0.90$. It was shown that the Bradley $3 \mathrm{~F} 12$ solution had an adequate fit in group $\mathrm{B}_{1-3}$, and a close to adequate $\mathrm{CFI}^{*}$ of 0.89 in group $\mathrm{B}_{4}$ (women with type 2 diabetes). A relatively large standardized residual of 0.22 was found for items 14 (dull) and 15 (tired) in group $B_{4}$.
Therefore, we assumed correlation between the error-terms of these items, resulting in an adequate fit of the model $\left(\mathrm{CFI}^{*}=0.93\right)$. The correlation between both error-terms was 0.52 . The factor loadings of the Bradley 3F12 model were all high, ranging from $|0 \cdot 49|$ to $|0.85|$ (Table 4). The correlations between Negative Well-being and Energy were in group $\mathrm{B}_{1-4}-0.63$, $-0.56,-0.63$ and -0.58 respectively. The correlations between Negative Well-being and Positive Well-being were $-0.71,-0.66,-0.063$ and -0.56 and the correlations between Energy and Positive Well-being were $0 \cdot 83,0 \cdot 68,0.66$ and 0.84 for the groups $B_{1-4}$ respectively.

The present sample had a relatively high level of education. Therefore, it was investigated whether the Bradley 3F12 model was stable across different levels of education. The fit of this model was tested separately for all five levels of education (Table 1). For people with general, senior (general) secondary education or higher vocational/university the Bradley $3 \mathrm{~F} 12$ model was accepted, with CFI*s of 0.93, 0.90 and 0.94 respectively. For the group of patients who only completed primary school and the group of patients who completed lower vocational education, the model was rejected (CFI* was 0.89 and 0.88 respectively). However, in both groups the CFI* could be improved to 0.92 when correlation was assumed between the error-terms of items 14 and 15 . The correlation between the error-terms of items 14 and 15 was 0.48 for the primary education group and 0.53 for the group of patients who completed lower vocational education (results not shown). 
Table 4. Final factor loadings after confirmatory factor analyses of the three-factor model with 12 items, in four homogenous groups of patients with diabetes

\begin{tabular}{|c|c|c|c|c|c|c|c|c|c|c|c|c|}
\hline \multirow{2}{*}{$\begin{array}{l}\text { Shortened } \\
\text { item content }\end{array}$} & \multicolumn{4}{|c|}{$\begin{array}{c}\text { Negative } \\
\text { Well-being }\end{array}$} & \multicolumn{4}{|c|}{ Energy } & \multicolumn{4}{|c|}{$\begin{array}{c}\text { Positive } \\
\text { Well-being }\end{array}$} \\
\hline & $\mathrm{B}_{1}$ & $\mathrm{~B}_{2}$ & $\mathrm{~B}_{3}$ & $\mathrm{~B}_{4}$ & $\mathrm{~B}_{1}$ & $\mathrm{~B}_{2}$ & $\mathrm{~B}_{3}$ & $\mathrm{~B}_{4}$ & $\mathrm{~B}_{1}$ & $\mathrm{~B}_{2}$ & $\mathrm{~B}_{3}$ & $\mathrm{~B}_{4}$ \\
\hline Crying spells & $0 \cdot 49$ & $0 \cdot 74$ & $0 \cdot 74$ & 0.57 & & & & & & & & \\
\hline Downhearted and blue & 0.77 & $0 \cdot 71$ & $0 \cdot 80$ & 0.72 & & & & & & & & \\
\hline Afraid for no reason & $0 \cdot 63$ & $0 \cdot 72$ & 0.82 & 0.73 & & & & & & & & \\
\hline Upset or feel panicky & 0.64 & 0.78 & 0.69 & 0.80 & & & & & & & & \\
\hline Energetic & & & & & $0 \cdot 74$ & $0 \cdot 78$ & 0.73 & $0 \cdot 81^{*}$ & & & & \\
\hline Dull & & & & & $-0 \cdot 74$ & -0.68 & $-0 \cdot 76$ & $-0.61^{*}$ & & & & \\
\hline Tired & & & & & $-0 \cdot 72$ & $-0 \cdot 71$ & $-0 \cdot 72$ & $-0 \cdot 50^{*}$ & & & & \\
\hline Fresh and rested & & & & & 0.65 & 0.72 & 0.64 & $0.66^{*}$ & & & & \\
\hline Happy with life & & & & & & & & & 0.76 & $0 \cdot 77$ & $0 \cdot 80$ & $0 \cdot 85$ \\
\hline Live life I want to & & & & & & & & & 0.82 & $0 \cdot 78$ & 0.75 & 0.79 \\
\hline Tackle daily tasks & & & & & & & & & 0.63 & $0 \cdot 67$ & $0 \cdot 65$ & 0.68 \\
\hline Cope with problems & & & & & & & & & $0 \cdot 69$ & $0 \cdot 71$ & 0.67 & $0 \cdot 67$ \\
\hline
\end{tabular}

$\mathrm{B}_{1}, 187$ men with type 1 diabetes; $\mathrm{B}_{2}, 167$ women with type 1 diabetes: $\mathrm{B}_{3}, 162$ men with type 2 diabetes; $\mathrm{B}_{4}, 189$ women with type 2 diabetes. * With correlated error between item 14 (dull) and 15 (tired).

\section{DISCUSSION}

The aim of the present study was to investigate the factor structure of the Dutch version of the W-BQ. In a two-factor solution, positively worded items loaded on the first factor (positive well-being) and negatively worded items loaded on the second factor (negative well-being). Factor analyses of other balanced questionnaires such as the State Trait Anxiety Inventory (STAI) and Zung's Self-rating Depression Scale (SDS) consistently seem to result in components reflecting the semantic modes of item presentation (Mook et al. 1991; Schotte et al. 1996).

The results of the three- and the four-factor solution supported the Bradley 3F12 model, since all the 12 items loaded in line with the findings of Bradley (1996). Using the CFI* as the most appropriate index of model-fit, CFAs in four subgroups provided further evidence for the Bradley 3F12 model. In the CFAs in group $\mathrm{B}_{4}$ (women with type 2 diabetes) and also in the two groups with the lowest level of education, the fit-index could be improved by freeing the errors of items 14 (dull) and 15 (tired). Error terms in a confirmatory factor analysis can be considered as factors unique to the measurement of each item in a questionnaire. The items 14 (dull) and 15 (tired) shared variance that happened not to be shared with items 13 (energetic) and 16 (fresh and rested). This finding can be explained by the wording of the items.
Item 14 and 15 are both negatively worded, while items 13 and 16 are formulated in a positive way.

The results of the EFAs and the CFAs did not support the widely used Bradley 4F22 model. This finding can be explained by the fact that the Bradley 4F22 model is based on EFAs that were performed with subgroups of 6-10 W-BQ items that corresponded with the a priori content of these items (Bradley et al. 1992). Yet all 22 items need to be a factor analysed simultaneously before conclusions can be drawn about the factor structure of the W-BQ as a whole. It was concluded that the Bradley 4F22 structure was confirmed, except for Energy (Wredling et al. 1995). This conclusion can be doubted since two depression and two anxiety items did not have significant factor loadings $(>|0 \cdot 30|)$ on their $a$ priori scale (Wredling et al. 1995). Ergo, the Bradley 4F22 structure is not based on convincing evidence and has not been replicated in other research yet. Based on the results of the present study, we recommend not using the Bradley 4F22 model in scoring the Dutch version of the W-BQ in patients with diabetes. For nonDutch versions of the $\mathrm{W}-\mathrm{BQ}$, the factorial validity of the Bradley 4F22 model and also the Bradley 3F12 model still need to be tested. Future research is also needed to test if both models can be replicated in groups of other patients. Pincus et al. (1997) found that the Bradley 4F22 model was not suitable for use in people with rheumatoid arthritis and concluded 
a two-factor model, composed of Positive wellbeing (six items) and Negative well-being (three items). Unfortunately, the Bradley 3F12 model was not tested in this study. In balanced scales that are constructed with both negatively worded and positively worded questions, the items that are in the opposite direction are usually recorded (e.g. ' 3 ' meaning 'all the time' becomes ' 0 ' meaning 'not at all'). But, responding that one is not at all tired, used up, worn out or exhausted, is not necessarily equivalent to feeling energetic all the time. Research in personal affective structure underlying self-report measures of affect suggests that positive and negative affect are two unipolar and largely independent dimensions (Schotte et al. 1996). The loss of the experience of positive well-being may precede the emergence of more negative states of mood (Watson et al. 1988). This implies that the factorial validity of the 12 -item $\mathrm{W}$-BQ might even be improved by adding new items with an energy content and also new items with a fatigue content, in order to construct an Energy scale and a Fatigue scale. This can be accomplished by splitting up the content of the four current double-barrelled Energy items. For example item 15 (I feel tired, worn out, used up, or exhausted) can easily be used to develop four negatively worded fatigue-items: 'I feel tired', 'I feel worn out', 'I feel used up' and 'I feel exhausted'. Using the current four Energy items, six new fatigue items and five new energy items can be developed. Future analyses are needed to study if the factorial validity of the W-BQ can be improved by rewriting the Energy items in this way.

Further research is also needed to investigate the clinical utility of the 12 -item $\mathrm{W}$-BQ as a screening instrument for depression and anxiety, in different groups of patients with a chronic disease as well as in the general population.

In conclusion, the results of the present study provide strong evidence for the three-factor structure with 12 items (W-BQ12), measuring positive well-being, energy and negative wellbeing. In a large sample of Dutch people with diabetes, this 12-item three-factor solution appeared to be stable across gender, type of diabetes and level of education.

The Diabetes Fund Netherlands (DFN) financially support this research (project number 95.805). The authors also wish to express their gratitude to the board and the members of the Dutch Organization of Patients with Diabetes (DVN, Diabetes Vereniging Nederland) for their kind cooperation in this study.

\section{REFERENCES}

Bech, P., Gudex, C. \& Staehr Johansen, K. (1996). The WHO (Ten) Well-being Index: validation in diabetes. Psychotherapy and Psychosomatics 65, 183-190.

Bentler, P. M. (1989). EQS. Structural Equations Program Manual: BMDP Statistical Software: Los Angeles.

Bradley, C. (1994). The Well-being Questionnaire (W-BQ). In Handbook of Psychology and Diabetes: a Guide to Psychological Measurement in Diabetes Research and Practice (ed. C. Bradley), pp. 89-109. Harwood Academic Publishers: Chur, Switzerland.

Bradley C. (1996). Well-being Questionnaire $(W-B Q)$ : Translation and Development of a Japanese Version, the $W$-BQ12 (Japanese). Report to M. Wada, Eli Lilly: Japan KK.

Bradley, C. \& Lewis, K. S. (1990). Measures of psychological wellbeing and treatment satisfaction developed from the responses of people with tablet-treated diabetes. Diabetic Medicine 7, 445-451.

Bradley, C. \& Gamsu, D. S. (1994). Guidelines for encouraging psychological well-being: report of a working group of the World Health Organization Regional Office for Europe and International Diabetes Federation European Region St Vincent Declaration Action Programme for Diabetes. Diabetic Medicine 11, 510-516.

Bradley, C., Meadows, K. \& Sowden, A. J. (1992). General Wellbeing and Satisfaction with Treatment Scales for Use with People with Insulin-Requiring Diabetes. Part 1: Psychometric Development and Retranslation of the English, French and German Versions. Report to Kirsten Staehr Johansen, WHO: Geneva.

Byrne, B. M. (1994). Structural Equation Modeling with EQS and EQS/Windows. Basic Concepts, Applications, and Programming. Sage Publications: California.

Coyne, J. C., Schwenk, T. L. \& Fechner-Bates, S. (1995). Nondetection of depression by primary care physicians reconsidered. General Hospital Psychiatry 17, 3-12.

Diabetes Control and Complications Trial Research Group (1993). The effect of intensive treatment of diabetes on the development and progression of long-term complications in insulin-dependent diabetes mellitus. New England Journal of Medicine 329, 977-986.

Floyd, F. J. \& Widaman, K. F. (1995). Factor analysis in the development and refinement of clinical assessment instruments. Psychological Assessment 7, 286-299.

Gavard, J. A., Lustman, P. J. \& Clouse, R. E. (1993). Prevalence of depression in adults with diabetes: an epidemiological evaluation. Diabetes Care 16, 1167-1178.

Lustman, P. J., Griffith, L. S., Freedland, K. E., Kissel, S. S. \& Clouse, R. E. (1998). Cognitive behavior therapy for depression in type 2 diabetes mellitus. Annals of Internal Medicine 129, 613-621.

Mook, J., Kleijn, W. Chr. \& Van der Ploeg, H. M. (1991). Symptom positively- and negatively-worded items in two popular self-report inventories of anxiety and depression. Psychological Reports 69, 551-560.

Penn, J. V., Boland, R., McCartney, J. R., Kohn, R. \& Mulvey, T. (1997). Recognition and treatment of depressive disorders by internal medicine attendings and housestaff. General Hospital Psychiatry 19, 179-184.

Petterson, T., Lee, P., Hollis, S., Young, B., Newton, P. \& Dornan, T. (1998). Well-being and treatment satisfaction in older people with diabetes. Diabetes Care 21, 930-935.

Peyrot, M. \& Rubin, R. R. (1997). Levels and risks of depression and anxiety symptomatology among diabetic adults. Diabetes Care 20, 585-590.

Pincus, T., Griffiths, J., Isenberg, D. \& Pearce, S. (1997). The Wellbeing Questionnaire: testing the structure in groups with rheumatoid arthritis. British Journal of Health Psychology 2, 167-174.

Pouwer, F., Snoek, F. J., Van der Ploeg, H. M., Heine, R. J. \& 
Brand, A. N. (1998). A comparison of the standard and the computerised versions of the Well-being Questionnaire (WBQ) and the Diabetes Treatment Satisfaction Questionnaire (DTSQ) Quality of Life Research 7, 33-38.

Rubin, R. R. \& Peyrot, M. (1992). Psychosocial problems and interventions in diabetes. A review of the literature. Diabetes Care 15, 1640-1657.

Schotte, C. K. W., Maes, M., Cluydts, R. \& Cosyns, P. (1996). Effects of affective-semantic mode of item presentation in balanced self-report scales: biased construct validity of the Zung Self-rating Depression Scale. Psychological Medicine 26, 1161-1168.

SPSS Inc. (1997). SPSS Base 7.5 for Windows Users Guide. SPSS Chicago.

Warr, P. \& Parry, G. (1982). Depressed mood in working-class mothers with and without paid employment. Social Psychiatry 17, 161-165.

Warr, P., Banks, M. \& Ullah, P. (1985). The experience of unemployment among black and white urban teenagers. British Journal of Psychology 76, 75-87.
Watson, D., Clark, L. A. \& Carey, G. (1988). Positive and negative affectivity and their relation to anxiety and depressive disorders. Journal of Abnormal Psychology 97, 346-353.

West, S. G., Finch, J. F. \& Curran, P. J. (1995). Structural equation models with nonormal variables. Problems and remedies. In Structural Equation Modeling. Concepts, Issues and Applications (ed. R. Hoyle), pp. 56-75. Sage Publications Inc.: California.

Wilhelm, K., Parker, G. \& Hadzi-Pavlovic, D. (1997). Fifteen years on: evolving ideas in researching sex differences in depression. Psychological Medicine 27, 875-883.

Wredling, R., Stålhammer, J., Adamson, U., Berne, C., Larsson, Y. \& Östman, J. (1995). Well-being and treatment satisfaction in adults with diabetes: a Swedish population-based study. Quality of Life Research 4, 515-522.

Zung, W. W. K. (1965). A self-rating depression scale. Archives of General Psychiatry 12, 63-70.

Zung, W. W. K. (1974). The measurement of affects: depression and anxiety. In Psychological Measurements in Psychopharmacology (ed. P. Pichot and R. Oliver-Martin), pp. 170-188. Karger: Basel. 